\title{
Thermal Hydraulic Performance in a Solar Air Heater Channel with Multi V-Type Perforated Baffles
}

\author{
Anil Kumar and Man-Hoe Kim * \\ School of Mechanical Engineering, Kyungpook National University, Daegu 41566, Korea; \\ anil_aheciit@yahoo.com \\ * Correspondence: kimmh@asme.org; Tel.: +82-53-950-5576; Fax: +82-53-950-6550 \\ Academic Editor: Francesco Calise \\ Received: 6 June 2016; Accepted: 14 July 2016; Published: 20 July 2016
}

\begin{abstract}
This article presents heat transfer and fluid flow characteristics in a solar air heater (SAH) channel with multi V-type perforated baffles. The flow passage has an aspect ratio of 10 . The relative baffle height, relative pitch, relative baffle hole position, flow attack angle, and baffle open area ratio are $0.6,8.0,0.42,60^{\circ}$, and $12 \%$, respectively. The Reynolds numbers considered in the study was in the range of 3000-10,000. The re-normalization group (RNG) $k-\varepsilon$ turbulence model has been used for numerical analysis, and the optimum relative baffle width has been investigated considering relative baffle widths of 1.0-7.0.The numerical results are in good agreement with the experimental data for the range considered in the study. Multi V-type perforated baffles are shown to have better thermal performance as compared to other baffle shapes in a rectangular passage. The overall thermal hydraulic performance shows the maximum value at the relative baffle width of 5.0.
\end{abstract}

Keywords: solar energy; heat transfer enhancement; friction factor; solar air heater (SAH) channel; perforated baffle

\section{Introduction}

Solar energy is one of the renewable and environment-friendly energy sources which can be used in our daily lives without imposing negative effects on the environment. It is generally used for a variety of engineering applications, among the generation of electric power, heating, cooking, and other applications. The solar air heater (SAH) is very simple and commonly used to heat air, and requires no maintenance [1]. However, the thermal performance of conventional SAH has been observed to be low because of the low Nusselt number from the heated plate to the fluid. The local heat transfer between the heated wall of SAH and flowing air can be improved by either (1) increasing the heat transfer surface area by means of extended and ribbed surfaces without enhancing the heat transfer rate; or (2) increasing the local heat transfer by means of the vortex generator in the form of baffles roughness on the absorber surface [2,3]. The roughness on the absorber plate can be introduced by various techniques casting, forming, welding ribs, baffles, and/or fixing thin circular wires. The use of baffles roughness on the underside of the heated wall can substantially enhance the local heat transfer of the SAH due to the rise in convective heat transfer rate from the plate to air.

Surface roughness is one of the first techniques to be considered as a means of augmenting forced convection heat transfer. In order to attain a higher convective heat transfer rate it is desirable that the flow at the heat transfer surface is turbulent [1-3]. However, the turbulence created in the core can increase the fan power exorbitantly. It is, therefore, desirable that the turbulence be created very close to the heat transfer surface, i.e., in the laminar sub-layer only, where the heat exchange takes place. However, as pointed out above, it is necessary that while creating turbulence to break the laminar sublayer, the core flow is not disturbed so as to avoid excessive losses. This can be achieved by using baffles roughness with roughness height being such that it does not project into the core but is of the 
height that just projects out of laminar sublayer. A number of experimental investigations involving roughness elements of different shapes, sizes, and orientations with respect to flow direction have been carried out in order to obtain an optimum arrangement of baffles roughness geometry $[4,5]$.

Various tabulators have been used to accelerate the heat transfer rate, including baffles, blocks, roughness, and winglets, depending upon the requirement needed. Tall height tabulators, such as baffles, are generally used for increasing heat transfer rates due to the turbulence in the flow field. Typical shapes of baffles are transverse, angled shaped, V-shaped, perforated, and have multiple blockages that can be fitted and bent away from the heated wall to produce turbulence in the flow field that results in an improvement of $N u_{\text {ave }}$ [6-12]. Furthermore, these baffles are modified to improve the thermo-hydraulic performance.

Numerous investigations have been carried out to improve the performance of baffles. Detailed descriptions of numerous experimental and numerical studies on baffles with different shapes, sizes, and orientations are discussed herein. Won et al. [6] reported the effect of angled rib baffles with an $\alpha$ value of $45^{\circ}, e / D$ of $0.078, P / e$ of 10 , and $\beta$ of $25 \%$, for a range of Reynolds (Re) values of $9000-76,000$. Khanoknaiyakarn [7] carried out an experimental study on $N u_{\text {ave }}$ and $f_{\text {ave }}$ for V-shaped baffles using a broad heated wall with a large $W c / H$ value, and the effects of the baffles on $N u_{\text {ave }}$ and $f$ ave were reported. Sriromreun et al. [8] experimentally determined the values of $N u$ and $f$ for an air passage with a Z-type blockage. Bopche and Tandale [9] reported the turbulent flow in a rectangular passage rough with a U-pattern blockage. Skullong et al. [10] carried out an analytical study on the turbulent passage flow and $N u_{\text {ave }}$ and $f_{\text {ave }}$ behaviour in a rectangular passage equipped with a blockage and groove blockage. Three different cases were experimentally studied with $e / H=0.5-2.0$ and $P / e=0.25$. They showed that the blockage-grooved with an upper wall at $e / H=0.5$ yielded the highest overall performance. Furthermore, Karwa and Maheshwari [11] performed an experimental study on the thermo-hydraulic performance for half and fully perforated blockage with Re values ranging from 2700 to 11,150 . They reported that half-perforated blockage with $P / e$ of 7.2 showed the maximum performance that is approximately $68.66 \%$ higher than the smooth wall with the same pumping power. Shin and Kwak [12] conducted an experimental study on the effect of the shape of perforation in the baffle roughened wall on $N u$ in a flow passage. They considered five geometries including wide, narrow, and circular hole configurations and reported the wider shape perforation showed superior thermal efficiency.

Zhou and Ye [13] carried out an experimental study investigating the turbulent fluid flow and heat transfer performance of a SAH rectangular passage with a curved trapezoidal winglet. Results were compared with rectangular, delta winglets, and trapezoidal. Bekele et al. [14] conducted indoor experiments to examine the effect of a delta-pattern blockage mounted on the heated wall of a rectangular passage with a small aspect ratio of 5.0:1.0. Chompookham et al. [15] conducted an experimental study on the effective efficiency performance of the winglet vortex type generators in a turbulent flow. Abene et al. [16] experimentally investigated the heat transfer augmentation of several different patterns of blockages attached to the top wall of a rectangular passage.

Ozgen et al. [17] investigated the thermal performance in a rectangular passage with a blockage attached to a heated wall. They reported that the collector efficiency could be improved by increasing the air velocity and the $N u$ data between the heated wall and the fluid. In addition, Thianpong et al. [18] conducted experimental work to examine the effects of collectors equipped with a twisted ring-type blockage in a rectangular passage. Eiamsa-ard et al. [19] reported the effect of thermal efficiency in a tube having different winglet tapes, namely, twisted tapes with straight delta and oblique delta winglets on twist and wing cut ratios. It was shown that the $N u_{\text {ave }}$ and $f_{\text {ave }}$ and thermal performance behaviour of the twisted tapes with an oblique delta winglet were better than those obtained in the cases of twisted tapes with oblique delta winglets, and in the case of typical twisted tapes. Chamoli and Thakur [20] reported the thermal performance of air passing through an air passage rough by V-type perforated blockage. Alam et al. [21] conducted an experimental study on the thermal hydraulic performance of a rectangular blockage with V-type rectangular perforated blocks fixed to a heated wall. 
Tamna et al. [22] experimentally and numerically investigated the thermal hydraulic performance of a rectangular passage with a multi V-type blockage fitted to a heated surface for the range of Re values from 4000 to 21,000 . Table 1 summarises the experimental investigations of some important baffle arrangements reported by various researchers.

Table 1. Previous experimental investigations in various baffle shapes in an air channel.

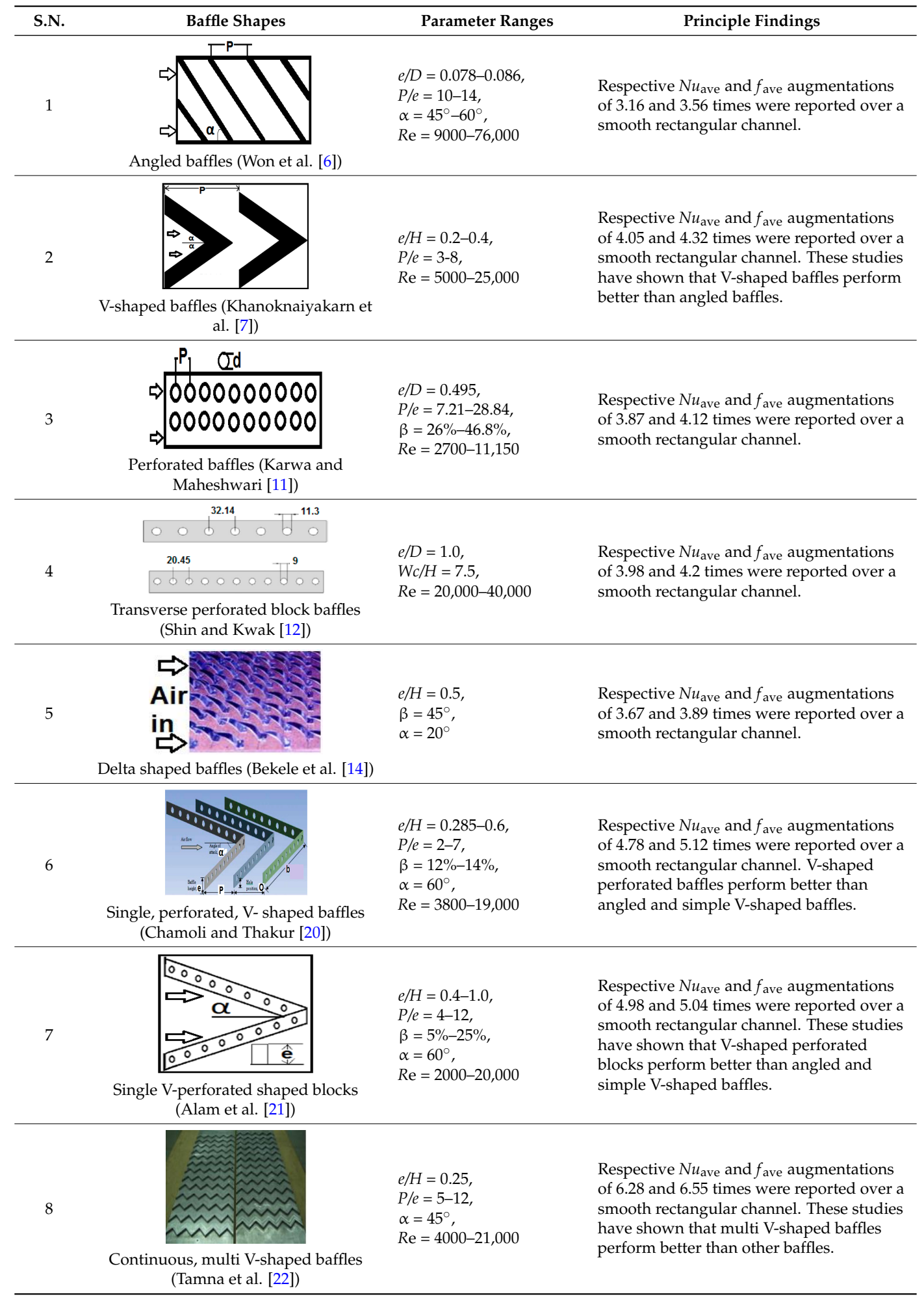


Computational fluid dynamics (CFD) is a numerical approach used to estimate detailed information for the fluid flow and heat transfer characteristics of a roughened rectangular channel. A critical review on heat transfer enhancement in a rectangular channel revealed that most investigations were carried out experimentally. However, only a few investigations are available those are based on CFD approaches [23-34]. Gawande et al. [23] conducted a numerical study on the effect of the transverse circular vortex type generator in an air channel. It was observed that the performance of the transverse circular vortex type generator in the channel was better than that of the smooth wall channel. Promvonge et al. [24] carried out a three-dimensional CFD analysis of heat transfer and fluid flow characteristics through a $30^{\circ}$ inline angled baffle as tabulators in an air channel. Garg et al. [25] numerically investigated the effect of transverse circular vortex generators for roughened air channels. Jedsadaratanachai and Boonloi [26] presented CFD results of flow and heat transfer characteristics in an isothermal square channel with a $30^{\circ}$ double V-baffles. It was found that the use of the double V-baffles led to higher heat transfer rates and pressure loss compared to the smooth channel with no baffle. Moreover, the rise of the blockage ratio and reduction of the pitch ratio led to heat transfer rate and pressure loss increases. Yadav et al. [27] conducted a CFD analysis on the overall thermal performance of a SAH with V-perforated downstream blocks attached to the heated wall. Several researchers numerically investigated rib roughened rectangular channels and reported the effects of rib shapes, rib spacing, rib height, rib flow attack angle, and channel aspect ratio on the heat transfer, pressure drop, and thermal performance [28-34]. Table 2 summarises the numerical investigations of some important baffle arrangements reported by various researchers.

Table 2. Summary of results from a previous computational fluid dynamics (CFD)-based study using various baffle shapes in an air channel.

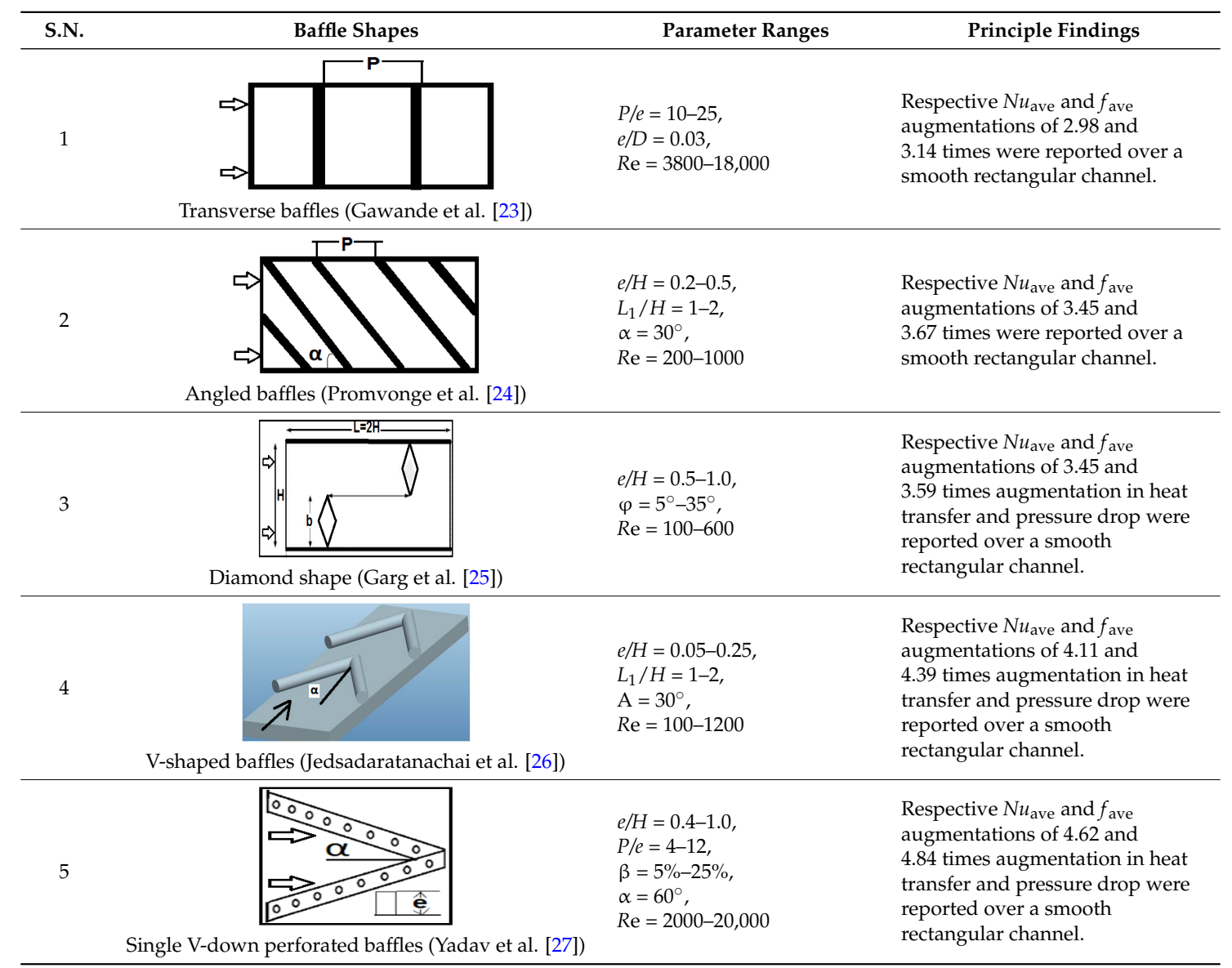


A literature review shows that the shape of the transverse baffles increases the heat transfer by air separation, reattachment, and creation of vortices upstream and downstream of the baffles, and that the air re-attaches in inter-baffle spaces. Angulations of the transverse baffles improve the heat transfer further on the explanation of movement of vortices on the length of the baffle wall and create secondary jets close to the leading end, which enhancement outcomes in local surface turbulence.

The advantage of V-down baffles is the generation of the two types of secondary stream jets as compared to only one in the case of angled baffles. In this case, the more the secondary stream jets, the higher the heat transfer rate. Further, making a perforation in the angulations blockage is found to increase the heat transfer by breaking and disturbing the secondary stream jets, and developing maximum level of turbulence in the downstream of the baffles. The use of multi V-type pattern baffles across the width of the passage is observed to improve the heat transfer by increasing the number of secondary stream jets more times in case of single type V-pattern baffle.

Recently, Chamoli and Thakur [20] explored the result of V-down perforated baffles on the heat transfer and fluid flow explanation of a rectangular passage. They concluded that the rise in the heat transfer rate attained was credited to the interaction of the secondary stream jets throughout the perforation, reattachment, and mixture with the main flow that creates extra turbulence. It is assumed that multi V-pattern perforated baffles will increase the heat transfer as compared to either single V-down perforated baffles, or baffles without perforated multi V-down baffles.

The purpose of this study is to numerically and experimentally investigate the air stream and heat transfer behaviour of the three-dimensional rectangular channel with rough in the form of multi V-type perforated baffles. In this investigation, the CFD ANSYS Fluent 6.3.26 Software (Fluent Inc., Lebanon, NH, USA) has been used to simulate the heat transfer and flow performance with multi V-type perforated baffles on the heated wall.

\section{Numerical Analysis}

\subsection{Description of Computational Model}

The rectangular air passage with multi V-down perforated baffles placed on one side of the heated plate is presented in Figures 1 and 2. The rectangular channel had a stream cross-section of $(W c)$ $300 \mathrm{~mm} \times(H) 30 \mathrm{~mm}$, with an aspect ratio $(W c / H)$ of 10.0 , and consisted of inlet and outlet parts separated by a test section. The hydraulic diameter $(D=4 A / P=2 H)$ was $54.54 \mathrm{~mm}$. The test unit distance end to end of the passage was $1000 \mathrm{~mm}$. The baffle rough can be explained by the data of the width of the rectangular channel $(W c)$, width of single V-perforated baffles $(W b)$, height of the baffles $(e)$, height of the channel $(H)$, hole position $(O)$ spacing between baffles $(P)$, size of hole $(d)$, and flow angle of attack $(\alpha)$. These rough parameters have been explained in the form of dimensionless rough parameters, i.e., the relative baffle width $(W c / W b)$, relative baffle height $(e / H)$, relative baffle hole position $(O / e)$, relative baffle pitch $(P / e)$, open area ratio $(\beta)$, and flow angle of attack $(\alpha)$. The blockage open area ratio is distinct as the ratio of the region perforation to the baffle frontal region, given by:

$$
\beta=\frac{n\left(\pi \times D^{2} / 4\right)}{b \times e}
$$

The choices for Re and blockage parameters for this study have been listed in Table 3 . The functional fluid was air in all of the cases studied. The velocity inlet was estimated at the inlet face of the duct. The air-inlet temperature was stable at $300 \mathrm{~K}$. The average inlet velocities of the stream were calculated using the Re. The inlet velocity of the air ranged between $0.9 \mathrm{~m} / \mathrm{s}$ and $2.9 \mathrm{~m} / \mathrm{s}$. A heat flux, $q=1000 \mathrm{~W} / \mathrm{m}^{2}$, was provided to the upper face of the collector, in a similar manner to the experimental setup of prior investigations [21,22]. The lower wall and the walls on the other sides were thought to be adiabatic. The exit boundary condition was considered to be at atmospheric pressure, i.e., $p=1.013 \times 10^{5} \mathrm{~Pa}$. 


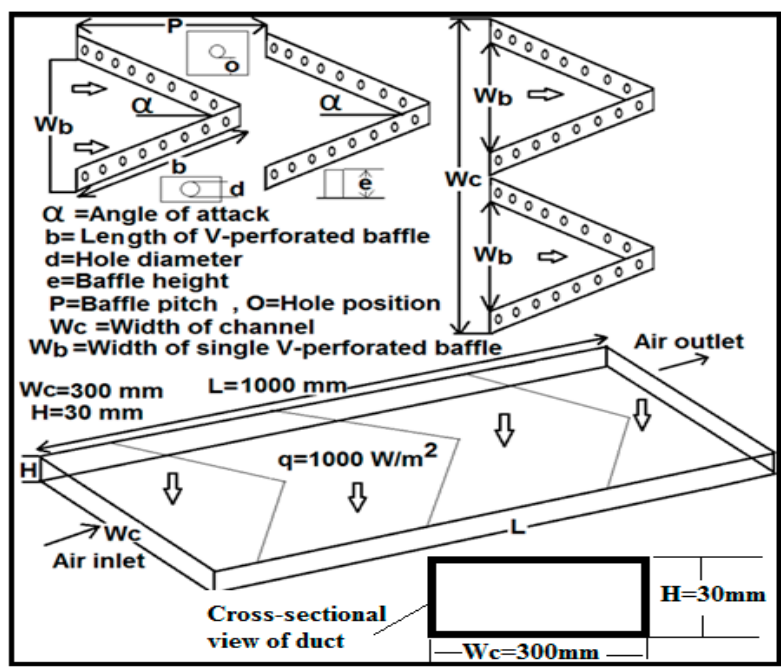

Figure 1. Multi V-shaped perforated baffle shape.
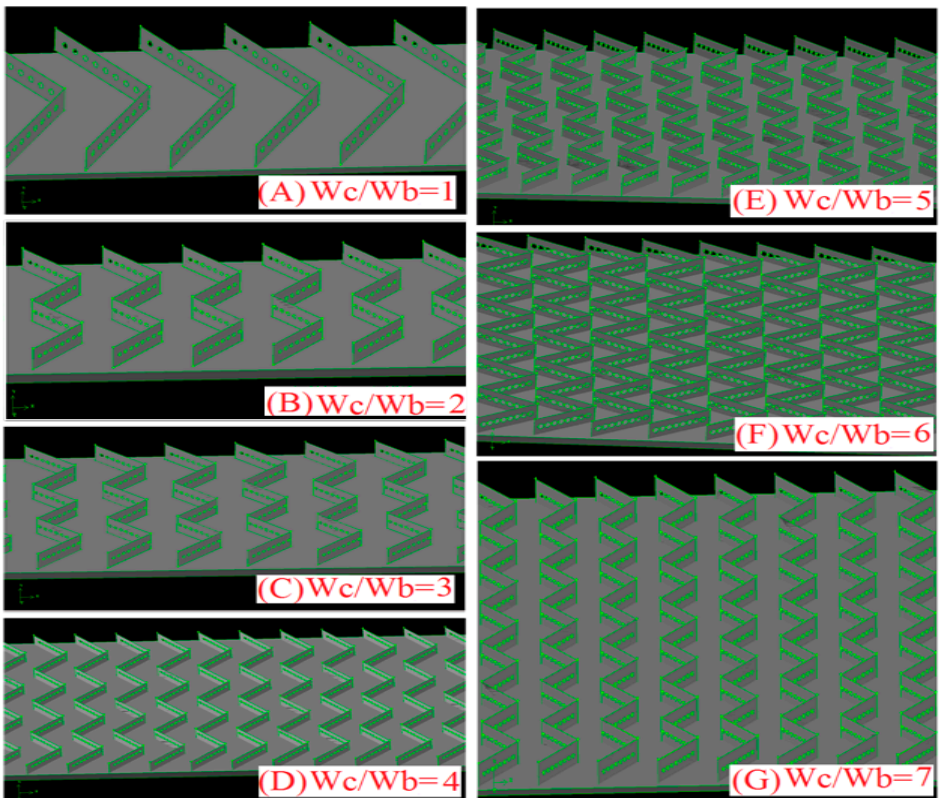

Figure 2. Computational domains for the CFD analysis. (A) $W c / W b=1 ;$ (B) $W c / W b=2$; (C) $W c / W b=3$; (D) $W c / W b=4 ;$ (E) $W c / W b=5$; (F) $W c / W b=6$; and (G) $W c / W b=7$.

Table 3. Range of operating parameters for CFD analysis.

\begin{tabular}{ccc}
\hline S.N. & Parameters & Ranges/Values \\
\hline 1 & Relative width ratio $(W c / W b)$ & $1.0-7.0$ \\
2 & Relative height ratio $(e / H)$ & 0.6 \\
3 & Relative pitch ratio $(P / e)$ & 8.0 \\
4 & Relative hole position $(O / e)$ & 0.42 \\
5 & Open area ratio $(\beta)$ & $12 \%$ \\
6 & Angle of attack $(\alpha)$ & $60^{\circ}$ \\
7 & Reynolds number $(R e)$ & $3000-10,000$ \\
8 & Uniform heat flux $(q)$ & $1000 \mathrm{~W} / \mathrm{m}^{2}$ \\
9 & Prandtl number $(P r)$ & 0.71 \\
10 & Duct aspect ratio $(W c / H)$ & 10 \\
\hline
\end{tabular}




\subsection{Governing Equations}

The numerical model for fluid flow and heat transfer in a SAH duct was developed under the following assumptions:

The flow is steady, fully developed, turbulent, and three-dimensional.

The thermal conductivity of the duct wall, absorber plate and roughness material are independent of temperature.

The duct wall, absorber plate, and roughness material are homogeneous and isotropic.

The working fluid (air) is assumed to be incompressible for the operating range of SAH since variation in density is much lower.

No-slip boundary condition is assigned to the walls in contact with the fluid in the model.

Radiation heat transfer and other heat losses are negligible.

The governing mathematical equations are the conservation of mass, momentum, and energy that can be described as follows [35]:

Continuity equation:

$$
\nabla \cdot(\rho \cdot \vec{v})=0
$$

Momentum equation:

$$
\nabla \cdot(\rho \cdot \vec{v} \cdot \vec{v})=-\nabla p+\nabla \cdot\left(\mu\left[\left(\nabla \vec{v}+\nabla \vec{v}^{T}\right)-\frac{2}{3} \nabla \cdot \vec{v} I\right]\right)+\rho \vec{g}
$$

Energy equation:

$$
\nabla \cdot(\vec{v}(\rho E+p))=\nabla \cdot\left(k_{\mathrm{eff}} \nabla T-h \vec{J}+\left(\mu\left[\left(\nabla \vec{v}+\nabla \vec{v}^{T}\right)-\frac{2}{3} \nabla \cdot \vec{v} I\right] \cdot \vec{v}\right)\right)
$$

where $k_{\text {eff }}$ is the effective conductivity $\left(k_{\text {eff }}=k+k_{t}\right)$.

The re-normalization group (RNG) $k-\varepsilon$ model was used for turbulent flow [35]. In this model, the turbulence kinetic energy $(k)$ and its rate of dissipation $(\varepsilon)$ are obtained from the following transport equations:

$$
\begin{gathered}
\frac{\partial}{\partial x_{i}}\left(\rho k u_{i}\right)=\frac{\partial}{\partial x_{j}}\left(\alpha_{k} \mu_{\mathrm{eff}} \frac{\partial k}{\partial x_{j}}\right)+G_{\mathrm{k}}+G_{\mathrm{b}}-\rho \varepsilon-Y_{M}+S_{k} \\
\frac{\partial}{\partial x_{i}}\left(\rho \varepsilon u_{i}\right)=\frac{\partial}{\partial x_{j}}\left(\alpha_{\varepsilon} \mu_{\mathrm{eff}} \frac{\partial \varepsilon}{\partial x_{j}}\right)+C_{1 \varepsilon} \frac{\varepsilon}{k}\left(G_{k}+G_{3 \varepsilon} G_{\mathrm{b}}\right)-C_{2 \varepsilon} \rho \frac{\varepsilon^{2}}{k}-R_{\varepsilon}+S_{\varepsilon}
\end{gathered}
$$

The model constants $C_{1 \varepsilon}$ and $C_{2 \varepsilon}$ in Equation (6) are 1.42 and 1.68, respectively.

In these equations $G_{\mathrm{k}}, S, G_{\mathrm{b}}$, and $Y_{M}$ represent the production of turbulence kinetic energy, the modulus of the mean rate of the strain tensor, the generation of turbulence kinetic energy due to buoyancy for ideal gas, and the contribution of the fluctuating dilatation in compressible turbulence to the overall dissipation rate, respectively. Correspondingly, they are defined by the following equations: $G_{\mathrm{k}}=\mu_{\mathrm{t}} S^{2}, S=\sqrt{2 S_{i j} S_{j i}}, G_{\mathrm{b}}=-g_{i} \mu_{\mathrm{t}} / \rho P r_{\mathrm{t}} \partial \rho / \partial x_{i}$ and $Y_{M}=2 \rho \varepsilon M_{\mathrm{t}}{ }^{2}$, where the quantities $\alpha_{\mathrm{k}}$ and $\alpha_{\varepsilon}$ are the respective inverse values of the effective Prandtl numbers for $k$ and $\varepsilon$. However, $S_{\mathrm{k}}$ and $S_{\varepsilon}$ are user-defined source terms. In addition, $R_{\varepsilon}=C_{\mu} \rho \eta_{1}{ }^{3}\left(1-\eta_{1} / \eta_{0}\right) / 1+\beta_{0} \eta_{1}{ }^{3} \varepsilon^{2} / k$, where $\eta_{1}=S k / \varepsilon$, $C_{\mu}=0.0845, \eta_{0}=4.38, \beta_{0}=0.012$.

\subsection{Grid Independency Test}

Figure 3 shows a schematic of the grid systems. Five different grid densities (respectively comprising 1789565, 1864345, 1964367, 2154376, and 2374635 cells) are used in order to select the suitable mesh size that adapts with near-wall modelling. The wall distance $y^{+}$is considered in the choice of the suitable near wall modelling. Figure 4 shows that the grid independence examination 
graph between the number of grids and the average Nusselt number for different values of $\left(W_{c} / W b\right)$ when all other baffles parameters were kept constant, and for a smooth wall with the RNG $k-\varepsilon$ turbulence model for five dissimilar grid densities of 1789565, 1864345, 1964367, 2154376, and 2374635 cells. It is observed that the relative deviation of the average Nusselt number among the solutions comprising 2154376 and 2374635 cells is less than $2 \%$ at $R e=7000$. Hence, the mesh with 2154376 cells with a close to wall element spacing $y^{+} \approx 2$ has been chosen for all the cases careful herein.

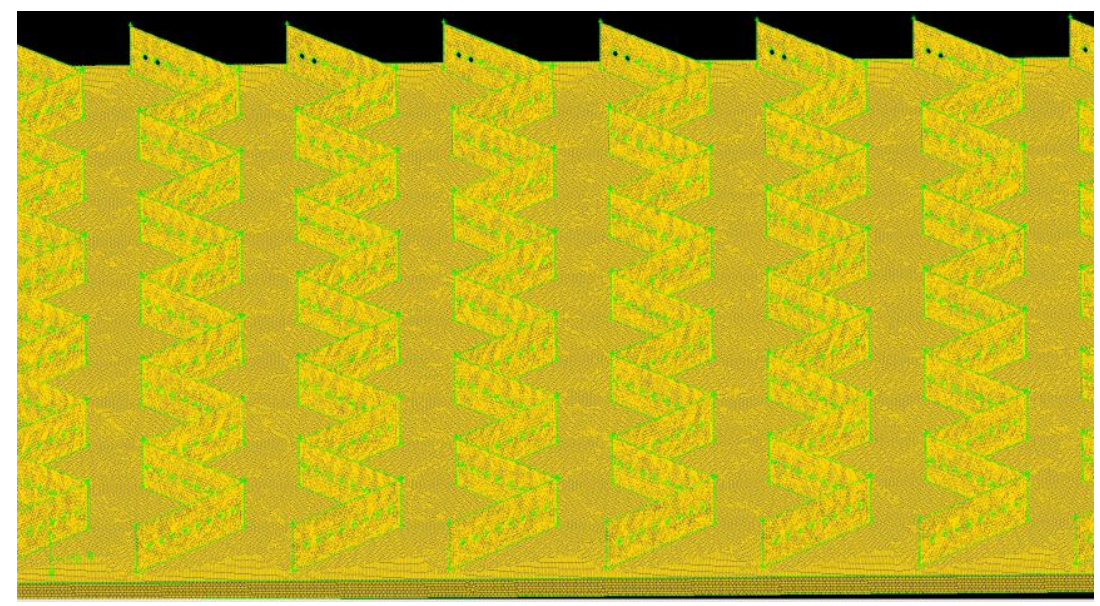

Figure 3. Schematic of the grid systems.

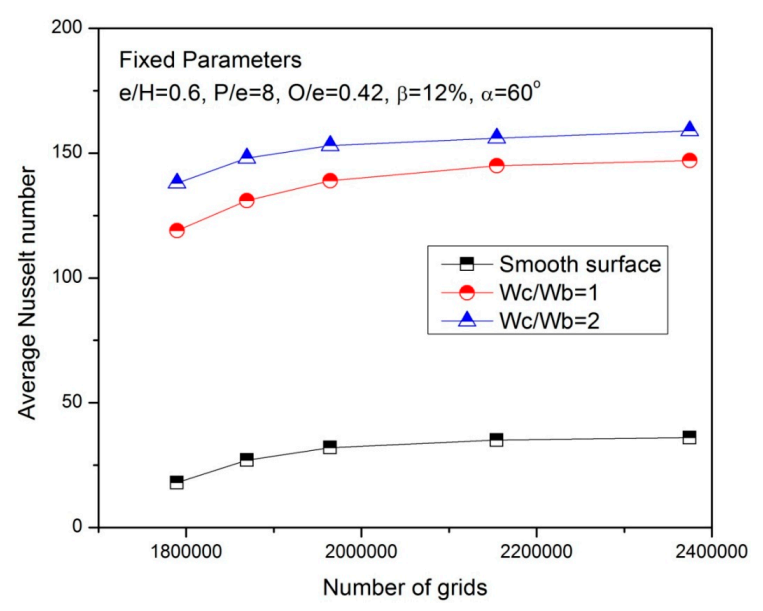

Figure 4. Variation in average Nusselt number with respect to the number of grids for a width ratio $(W c / W b=1.2)$ and a smooth surface rectangular channel with the Reynolds number of 7000.

\subsection{Selection of Turbulence Model}

Previous investigations [29-34] indicated that they used different turbulence models for their studies in air flow channels, such as realizable $k-\varepsilon$ model, RNG $k-\varepsilon$ model, standard $k-\varepsilon$ model, standard $k-\omega$, and shear stress transport $k-\omega$ model. Therefore, numerical predictions were compared with available experimental data and the RNG $k-\varepsilon$ model was selected in this study because it was found to be the better one. The data of $N u_{\text {ave }}$ and $f_{\text {ave }}$ determined from the CFD results (RNG $k-\varepsilon$ model) for single V-type perforated baffle and were compared with the values obtained from the correlations described by Equation (7) for $N u_{\text {ave }}$ and Equation (8) for $f_{\text {ave }}$.

The $N u_{\text {ave }}$ correlation for the single V-type perforated baffle [20] is shown as follow: 


$$
\begin{gathered}
N u=0.029 \times R e^{0.7848} \times(P / e)^{0.3007} \times(e / H)^{-0.6774} \times \beta^{-0.3571} \exp \left(-0.254 \ln (P / e)^{2}\right) \\
\times \exp \left(-0.4406 \ln (e / H)^{2}\right) \exp \left(-0.0863 \ln (\beta)^{2}\right)
\end{gathered}
$$

The $f_{\text {ave }}$ correlation for the single V-type perforated baffle [20] is shown as follows:

$$
f=0.632 \times R e^{-0.18} \times(P / e)^{-0.16} \times(e / H)^{1.05} \beta^{-0.13}
$$

Comparisons of the experimental and numerical values for $N u_{\text {ave }}$ and $f_{\text {ave }}$ as a function of $R$ e are shown in Figure 5. The average deviations of $N u_{\text {ave }}$ and $f_{\text {ave }}$ obtained using the RNG $k-\varepsilon$ turbulence model are $\pm 8.34 \%$ and $\pm 9.73 \%$, respectively, from the experimental results [20].
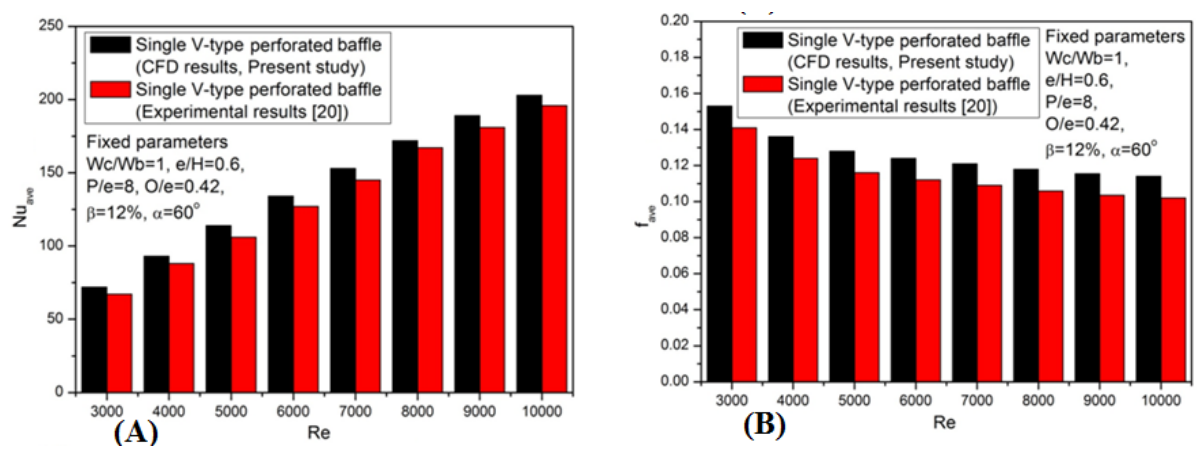

Figure 5. Comparison of experimental results with CFD results of single V-type perforated baffle: (A) $N u_{\text {ave }}$ and $(\mathbf{B}) f_{\text {ave }}$.

\subsection{Solution Method}

A three-dimensional model of the flow domain used for numerical analysis was built using ANSYS Fluent 6.3.26 Software. Grid was generated in GAMBIT Software. Meshed model was then exported to ANSYS Fluent 6.3 .26 for analysis. The continuity equation, energy equation, and the Navier-Stokes equations in their steady, incompressible form, along with the associated boundary conditions, were solved using the multipurpose finite volume-based CFD software package, ANSYS Fluent 6.3.26. In the present numerical study, RNG $k-\varepsilon$ turbulence model with 'enhanced wall treatment' was used. In the discretization of governing equations, SIMPLE (semi-implicit method for pressure linked equations) algorithm was used in pressure-velocity coupling as suggested by Kumar and Kim [34]. This algorithm was developed by Karmare and Tikekar [29] and is based on a predictor-corrector approach. Double precision pressure-based solver was selected in order to solve the set of equations used. Second order upwind discretization scheme was selected for all the transport equations as suggested by Kumar and Saini [30]. Whenever convergence problems were noticed, the solution was started using the first order upwind discretization scheme and continued with the second order upwind scheme. The governing equations for mass and momentum conservation were solved with a segregated approach in steady state, where equations are sequentially solved with implicit linearization. In the present simulation, the convergence criteria between two consecutive iterations was set to be the relative deviation less than $10^{-6}$ for energy equation and less than $10^{-3}$ for the solution in velocity and continuity equation.

\subsection{Data Reduction}

The values of Reynolds number, Nusselt number, average Nusselt number, friction factor and thermal-hydraulic performance have been calculated using the following equations $[15,17,19-23]$ :

The Reynolds number:

$$
R e=\frac{\rho u D}{\mu}
$$


The heat transfer performance is calculated using the $N u$, which can be obtained from:

$$
N u=\frac{h L}{k}
$$

The average $N u_{\text {ave }}$ can be obtained from:

$$
N u_{\mathrm{ave}}=\frac{1}{L} \int N u(x) \partial x
$$

The $f$ is calculated using the following equation:

$$
f=\frac{(\Delta p / L) H}{(1 / 2) \rho u^{2}}
$$

where $\Delta p$ is the pressure drop through the length of the duct, $L$.

The thermal enhancement factor $(\eta)$ is defined as the ratio of the heat transfer coefficient of an augmented surface $(h)$ to that of a smooth channel without ribs $\left(h_{\mathrm{s}}\right)$ at an equal pumping power.

$$
\eta=\frac{h}{h_{s}}=\left(N u_{\text {ave }} / N u s_{\text {ave }}\right) /\left(f_{\text {ave }} / f s_{\text {ave }}\right)^{0.33}
$$

where $N u_{\text {ave }}$ and $f_{\text {ave }}$ are the average Nusselt number and friction factor for the smooth duct, respectively.

\section{Results and Discussion}

The CFD analysis has been performed for a roughened rectangular channel with multi V-down perforated baffles on a heated plate, and the results are discussed in this section.

\subsection{Heat Transfer and Fluid Flow}

The outcome of the $W c / W b$ on the $N u_{\text {ave }}$ and $f_{\text {ave }}$ for air stream are presented in a rectangular channel. The results have been comparable with those obtained in the case of a smooth wall channel working under similar numerical circumstances.

The results of $N u_{\text {ave }}$ have been shown as a function of $R e$ for the different values of $W c / W b$ in Figure 6, and for constant values of the other parameters, such as $e / H=0.6, P / e=8.0, O / e=0.42$, $\beta=12 \%$, and $\alpha=60^{\circ}$. It has been seen that the $N u_{\text {ave }}$ increases with an increase in the $W c / W b$, and attains a maximum value matching to a $W_{c} / W b$ value of 5.0 in the range of the parameters investigated. In all cases, the presence of a wall with multi V-down perforated baffles produces higher $N u_{\text {ave }}$ compared to the case of a smooth wall, as expected. The V-down perforated baffles can lead to better $N u_{\text {ave }}$ performance because of the secondary stream jets induced by the top part of the baffles. These secondary stream jets have the form of more than one counter rotating vortex, which carry cold air from the middle core region towards the baffle walls. These secondary flow jets interact with the main stream, thereby affecting the flow re-attachment and re-circulation between baffles, and interrupt the boundary layer enlargement downward of the re-attachment regions.

Figure 7 presents the contour map of the turbulent intensity for different $W c / W b$ values, while other roughness parameters are maintained constant and equal to $e / H=0.6, P / e=8.0, \beta=12 \%$, $O / e=0.42, \alpha=60^{\circ}$, and $R e=5000$. It can be observed that doubling the value of the width ratio $\mathrm{Wc} / \mathrm{Wb}$ also increases the number of leading and trailing ends as well as the secondary flow cells, thereby resulting in a considerable enhancement in the heat transfer, as clearly observed in Figure 7 . However, the increase in $N u_{\text {ave }}$ continues only up to a $W c / W b$ of 5.0. Subsequently, a further increase in the baffle width results in the reduction of the $N u_{\text {ave. }}$. The V-pattern configuration of the baffles induces strong secondary stream jets along the limbs and a higher level of mixing and turbulence when the jets passing from the various perforations re-attach and mix with the main stream. 


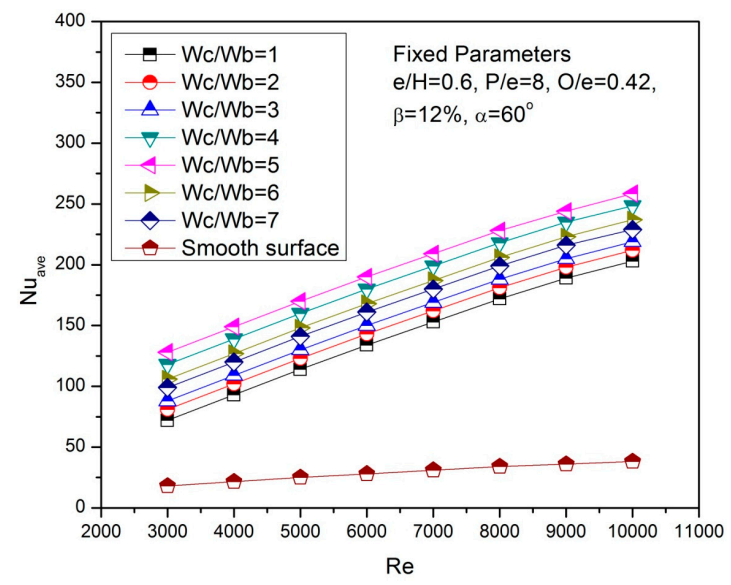

Figure 6. Variation in the average Nusselt number $N u_{\text {ave }}$ with respect to Reynolds number for different $W c / W b$.
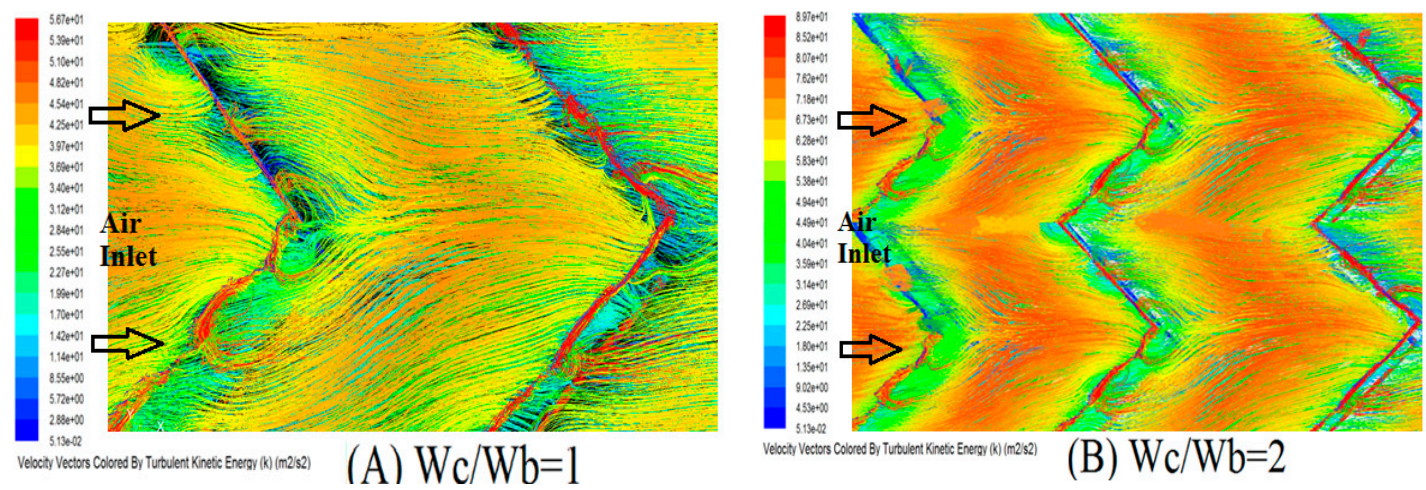

Figure 7. Contour plot of turbulent kinetic energy for: (A) $W c / W b=1$; and (B) $W c / W b=2(e / H=0.6$, $P / e=8.0, O / e=0.42, \beta=12 \%, \alpha=60^{\circ}$, and $\left.\operatorname{Re}=5000\right)$.

Introduction of the perforated multi V-baffles allows the release of the secondary stream jets and the mixing with the main stream through the perforations, as shown in Figure 8.

Use of baffle roughness on a heated wall substantially increases the heat transfer from the heated wall of rectangular channels. However, it results in corresponding increases in frictional losses. Figure 9 shows the variation in the $f_{\text {ave }}$ with $R$ e for different values of $W_{c} / W b$, while all other rough parameters are maintained constant at $e / H=0.6, P / e=8.0, O / e=0.42, \beta=12 \%$, and $\alpha=60^{\circ}$.It has been observed from this plot that the $f_{\text {ave }}$ decreases with increases in the Re values, for all values of $W c / W b$. It can also be seen that the $f_{\text {ave }}$ increases monotonically with increases in $W c / W b$ values. The maximum value of the $f_{\text {ave }}$ has been observed at a value of $W c / W b$ of 7.0. This is due to fact that angulation of the baffles helps in the development of the secondary stream jets. Increasing the value of $W_{c} / W b$ would lead to an increased number of secondary stream jets, which in turn increases the value of the $N u_{\text {ave }}$ up to 5.0. Furthermore, increases in $W c / W b$ beyond 5.0 could lead to the partition of flow from the top baffle surface, and to a subsequent reduction in $N u_{\text {ave. }}$. However, the values of $f_{\text {ave }}$ increase continuously due to the mixing of an increased number of secondary flows after being issued from the perforations and after their re-attachment with the heated surface. For this reason, this mixing increases heat transfer from the plate to air, but also facilitates large pressure drops through the flow across the passage. 

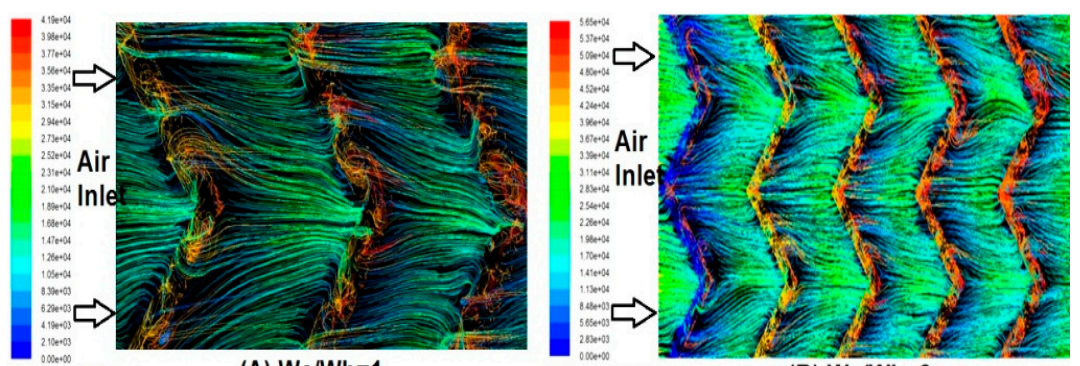

(A) $\mathrm{Wc} / \mathrm{Wb}=1$

(B) $\mathrm{Wc} / \mathrm{Wb}=2$
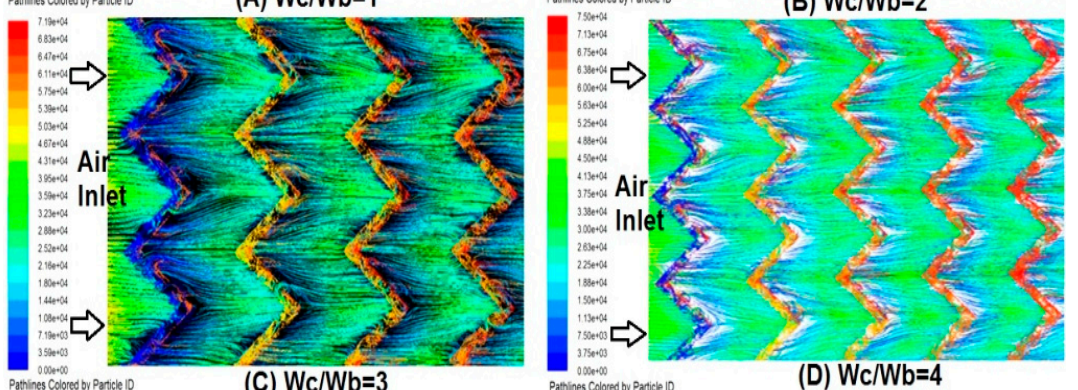

(C) $\mathrm{Wc} / \mathrm{Wb}=3$

(D) $\mathrm{Wc} / \mathrm{Wb}=4$

Figure 8. Contour plot of path lines for (A) $W c / W b=1,(\mathbf{B}) W c / W b=2,(\mathbf{C}) W c / W b=3$, and (D) $W c / W b=4\left(e / H=0.6, P / e=8.0, O / e=0.42, \beta=12 \%, \alpha=60^{\circ}\right.$, and $\left.\operatorname{Re}=5000\right)$.

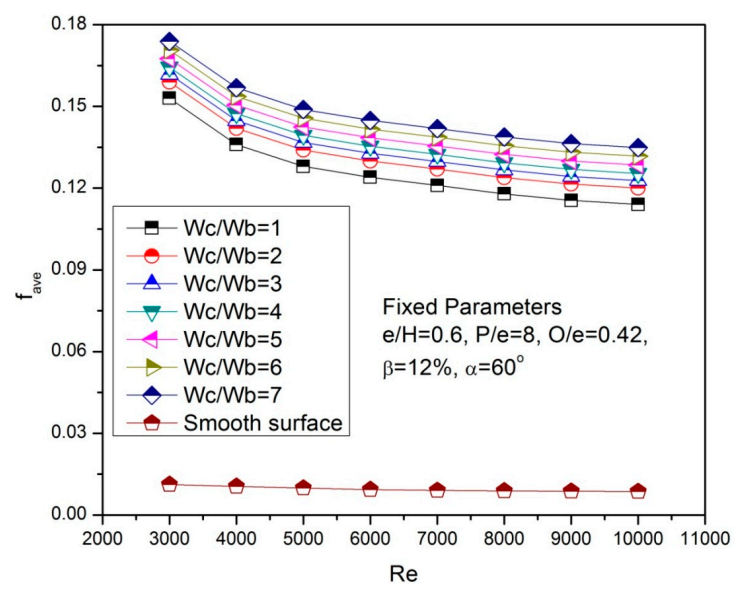

Figure 9. Variation of friction factors $\left(f_{\text {ave }}\right)$ with respect to the Reynolds number.

\subsection{Thermo-Hydraulic Performance}

Analysis of the thermal and friction behaviours shows that improvement in thermal performance is, in general, accompanied with a friction penalty owing to a resultant augmentation of the friction factor. Consequently, it is necessary to establish the baffle shapes that will result in the maximal enhancement in heat transfer with the least frictional power penalty. This can be achieved by concurrent thought of thermal as well as hydraulic performances, i.e., the thermo-hydraulic performance parameter, $\eta$, which indicates the comparison of the heat transfer enhancement for a roughened channel to a smooth (without rough) channel for the same pumping power requirements, and for fully developed turbulent flows. The following Equation (14) represents the thermo-hydraulic performance parameter [31-34,36,37]:

$$
\eta=\left(N u_{\text {ave }} / N u s_{\text {ave }}\right) /\left(f_{\text {ave }} / f s_{\text {ave }}\right)^{0.33}
$$

An increased parameter value indicates a relatively more efficient use of the augmentation device, and can be used to evaluate the performance of the number of preparations in order to decide the best one among these. The variation in $\eta$ is shown in Figure 10 for different values of $W c / W b$. It can be 
observed that the value of the thermo-hydraulic performance parameter $(\eta)$ is maximized for a $W c / W b$ value of 5.0 at any $R e$ value, considered the current investigation.

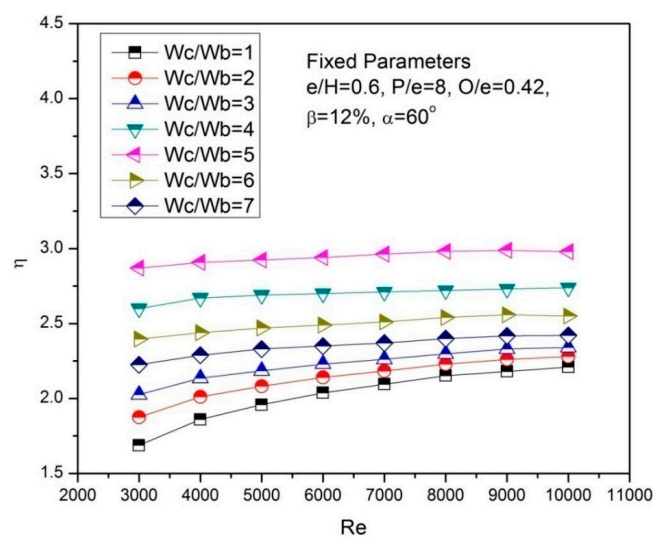

Figure 10. Variation of the thermo-hydraulic performance parameters $(\eta)$ with $W c / W b$.

\section{Comparison Computational Fluid Dynamics Results with Experimental Data}

\subsection{Experimental Setup Details}

A schematic diagram of an experimental setup is shown in Figure 11. The setup comprised a rectangular wooden channel coupled to a centrifugal blower through a circular galvanized iron (GI) pipe. The rectangular channel had $W c$ of $300 \mathrm{~mm}, H$ of $30 \mathrm{~mm}$, and $W c / H$ of 10 . It consisted of inlet and exit sections that were interposed by test sections. The upper wall of the test section was an aluminum heated plate that was heated by an electric heater which provided a uniform heat flux over the whole top wall. Air mass flow rate through the SAH was measured with a calibrated orifice meter that was attached to a U-tube manometer. Air flow was regulated with two gate valves that were coupled in the lines. The temperature was calculated at different locations with calibrated $0.3 \mathrm{~mm}$ diameter copper constantan thermocouples, which were coupled to a digital micro voltmeter (DMV) to illustrate the temperature. The pressure drop crossways the test section was deliberate with a micro-manometer having least count of $0.001 \mathrm{~mm}$ of water.

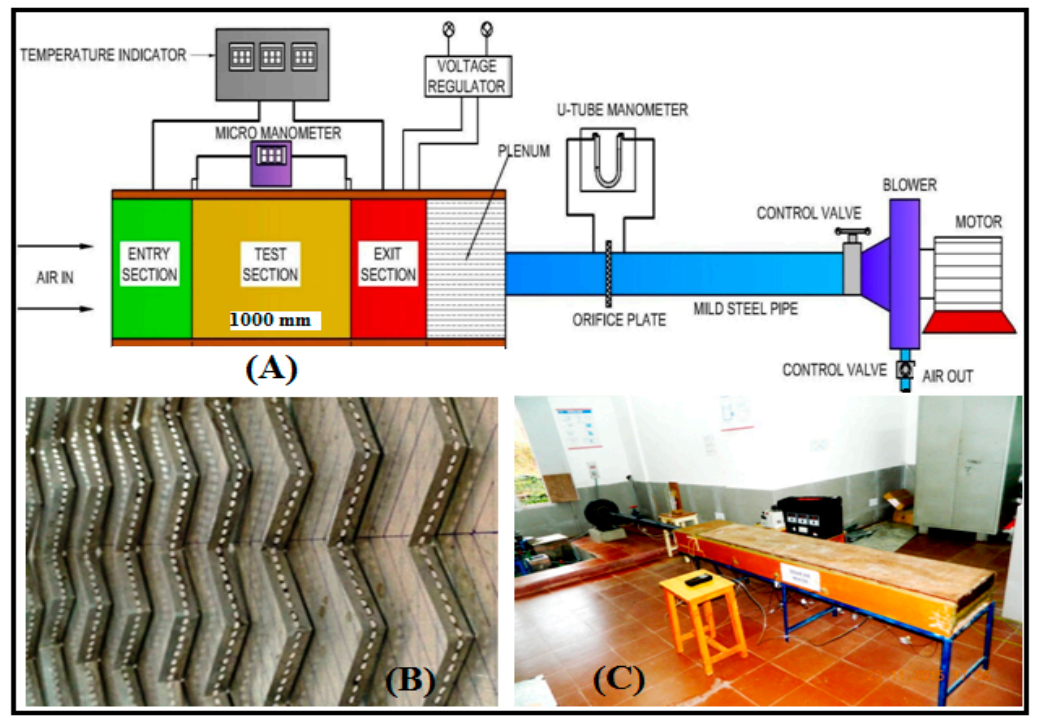

Figure 11. Details of experimental setup: (A) line diagram experimental setup; (B) photographic view of multi V-perforated baffle; and (C) photographic view of experimental setup. 


\subsection{Uncertainty Analysis}

An uncertainty analysis has been carried to estimate the errors involved in experimental data measurement. The uncertainty is estimated based on errors associated with measuring instruments [38]. The maximum possible measurement errors in the values of major parameters are given below:

$\begin{array}{ll}\text { Mass flow rate }\left(m_{\mathrm{a}}\right) & 2.67 \% \\ \text { Reynolds number }(R e) & 5.87 \% \\ \text { Heat transfer coefficient }\left(h_{\mathrm{t}}\right) & 6.23 \% \\ \text { Average Nusselt number }\left(N u_{\text {ave }}\right) & 5.98 \% \\ \text { Average friction factor }\left(f_{\text {ave }}\right) & 4.18 \%\end{array}$

\subsection{Validation of Computational Fluid Dynamics Results Using Experimental Data}

For the validation of the present numerical model, the numerical results (average Nusselt number, average friction factor and thermohydraulic performance) of a rectangular channel with multi V-type perforated baffle attached on a heated plate are compared with experimental results under similar experimental operating conditions. For validation of present CFD outcomes, baffle roughened parameters were selected such as $W c / W b=5.0, e / H=0.6, P / e=8.0, O / e=0.42, \beta=12 \%$, and $\alpha=60^{\circ}$. Relative baffle width ratio $(W c / W b)$ was selected as 5.0 based on the optimal value of this parameter based on the CFD results. Figure 12 shows the comparison of the CFD results with experimental data of the average Nusselt number, average friction factor as a function of the Reynolds number. The average deviations of the average Nusselt numbers, friction factors, and thermohydraulic performance are $\pm 7.98 \%, \pm 9.56 \%$, and $\pm 8.56 \%$, respectively.
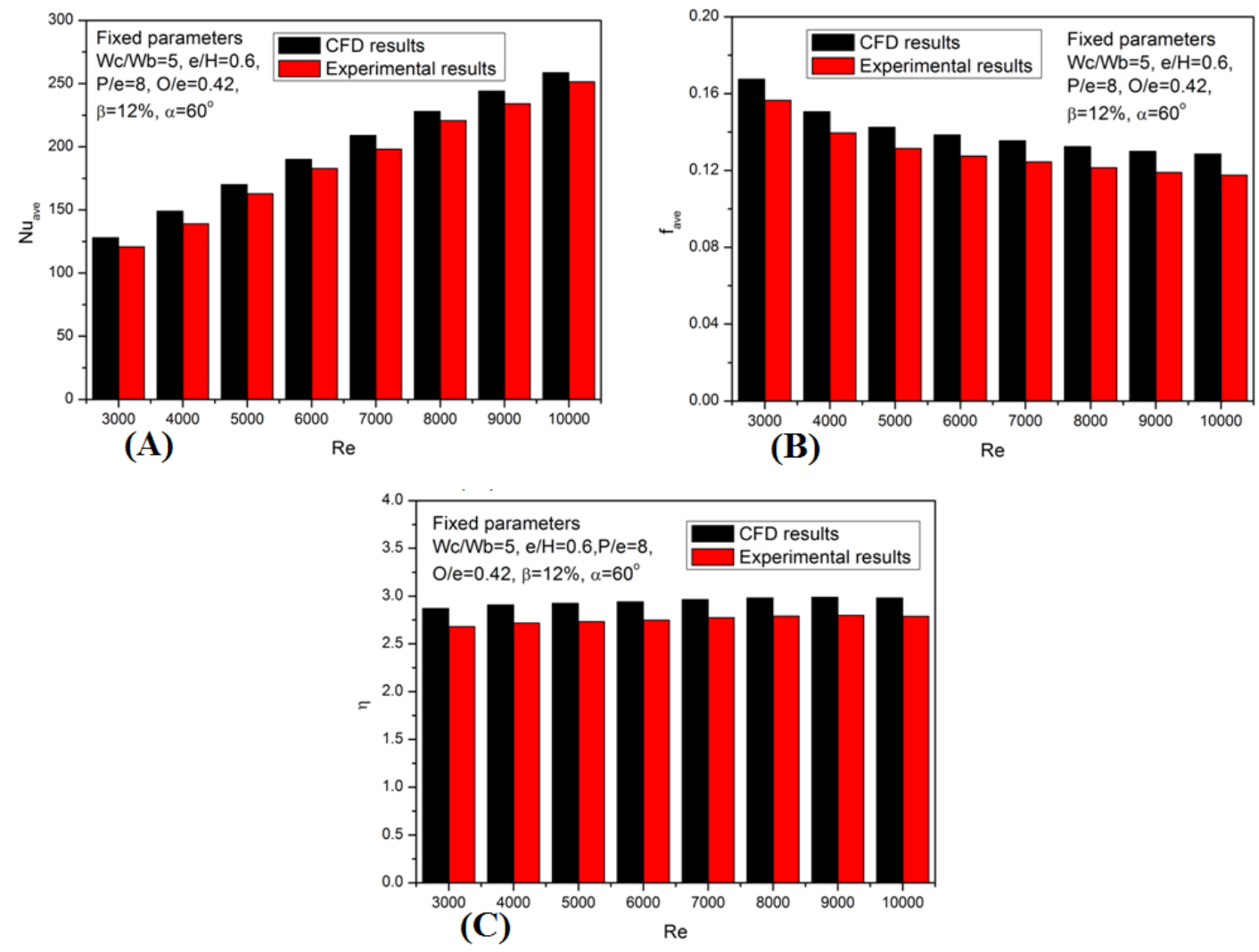

Figure 12. Comparison of CFD results with experimental results: (A) Nusselt number; (B) friction factor; and (C) thermal-hydraulic performance. 
The values of $\eta=\left(N u_{\text {ave }} / N u s_{\text {ave }}\right) /\left(f_{\text {ave }} / f_{s_{\text {ave }}}\right)^{0.33}$ of the multi V-shaped perforated baffles have been compared with the values for other baffle shapes in a rectangular channel, as shown in Figure 13. It is seen that the multi V-shaped perforated baffle shape results in the best thermo-hydraulic performance $\eta=\left(N u_{\text {ave }} / N u s_{\text {ave }}\right) /\left(f_{\text {ave }} / f s_{\text {ave }}\right)^{0.33}$ among all the shapes investigated.

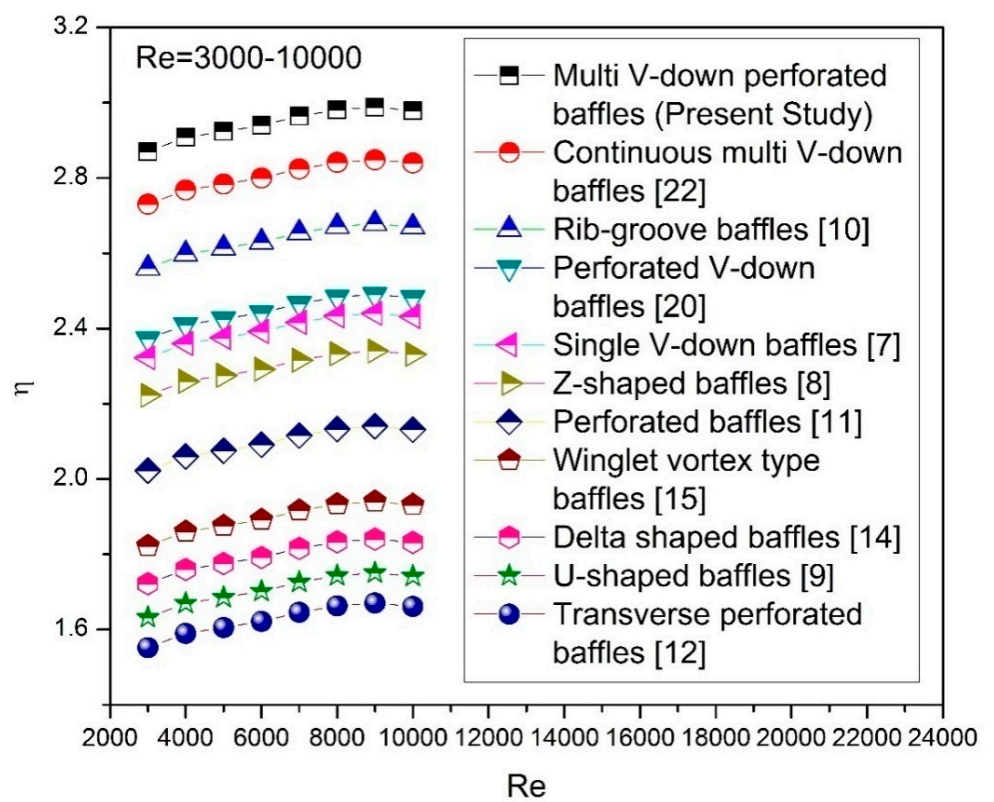

Figure 13. Comparison of various baffle shapes in a rectangular channel.

\section{Conclusions}

The heat transfer and pressure drop characteristics have been investigated in multi V-pattern perforated baffle attached on one broad wall, which is exposed to uniform heat flux in a rectangular channel. The effects of baffle width ratios on average Nusselt number, average friction factor, and thermal-hydraulic performance have been also studied for Reynolds number in the range of 3000-10,000. Multi V-shaped perforated baffles show a considerable enhancement in the heat transfer rate, and the heat transfer enhancement strongly depends on the relative baffle width ratio. The average Nusselt number increases whereas the average friction factor decreases with an increase in the Reynolds number. The values of average Nusselt numbers and friction factors are found to be higher for multi V-shaped perforated baffles compared to those for a rectangular channel without baffles. This is attributed to the change in the fluid flow characteristics due to the baffle roughness that causes generation of secondary flows. The maximum values of average Nusselt number and friction factor are observed for multi V-shaped perforated baffles width ratio of 5.0 and 7.0, respectively. The optimum value of the thermo-hydraulic performance for multi V-shaped perforated baffles in a rectangular channel has been found at the baffle width ratio of 5.0. Multi V-shaped perforated baffles have also been shown to be thermo-hydraulically better in comparison to other baffle shapes in a rectangular channel. The outcomes of 3-D CFD analysis are in good agreement with the experimental data, and thus the current CFD model can be used for the analysis of the new baffle shapes in rectangular channel.

Acknowledgments: This research was supported by the Technology Innovation Program (Grant No. 10052926) by the Ministry of Trade, Industry \& Energy, Korea.

Conflicts of Interest: The authors declare no conflict of interest. 


\section{Nomenclature}

B

$C p$

D

d

$e$

$e / H, e / D$

$f$

$f_{\text {ave }}$

$f s_{\text {ave }}$

H

$h_{\mathrm{t}}$

$k$

Ka

$L_{1}$

$L_{\mathrm{t}}$

$m_{\mathrm{a}}$

$n$

$\mathrm{Nu}$

$\mathrm{Nus}$

$N u_{\text {ave }}$

Nus ave

O

O/e

$P$

P/e

$p$

Pr

$\mathrm{Pr}_{\mathrm{t}}$

$q$

$Q_{\mathrm{u}}$

$R_{\mathrm{e}}$

$T$

$T_{\mathrm{f}}$

$T_{\mathrm{i}}$

$T_{\mathrm{o}}$

$T_{\mathrm{p}}$

$\underset{\vec{v}}{\overrightarrow{u_{\mathrm{i}}}}$

V

$W_{c} / H$

Wc

$\mathrm{Wb}$

$\mathrm{Wc} / \mathrm{Wb}$

$x$

$y^{+}$

$\left(\Delta_{p}\right)_{\mathrm{d}}$

$\left(\Delta_{p}\right)_{\mathrm{o}}$
Length of the baffle, $\mathrm{m}$

Specific heat of air, $\mathrm{J} / \mathrm{kgK}$

Hydraulic diameter of channel, $\mathrm{m}$

Hole diameter of perforated baffles, $\mathrm{m}$

Baffle height, $\mathrm{m}$

Relative baffle height

Friction factor of baffle roughened wall

Average friction factor of baffle roughened wall

Average friction factor of smooth channel

Height of channel, $\mathrm{m}$

Convective heat transfer, $\mathrm{W} / \mathrm{m}^{2} \mathrm{~K}$

Turbulent kinetic energy, $\mathrm{m}^{2} / \mathrm{s}^{2}$

Thermal conductivity of air, $\mathrm{W} / \mathrm{mK}$

Axial pitch length, $\mathrm{m}$

Length of test section, $\mathrm{m}$

Mass flow rate of fluid, $\mathrm{kg} / \mathrm{s}$

Number of drilled holes

Nusselt number for baffle roughened wall

Nusselt number for smooth wall

Average Nusselt number for baffle roughened wall

Average Nusselt number for without baffle wall

Hole location from bottom of baffle, $m$

Relative baffle hole location

Distance between baffles, $\mathrm{m}$

Relative baffles pitch

Pressure, Pa

Prandtl number

Turbulent Prandtl number

Heat flux, $\mathrm{W} / \mathrm{m}^{2}$

Useful heat gain, $\mathrm{W}$

Reynolds number

Temperature, $\mathrm{K}$

Average temperature of fluid, $\mathrm{K}$

Inlet temperature of fluid, $\mathrm{K}$

Outlet temperature of fluid, $\mathrm{K}$

Plate temperature of fluid, $\mathrm{K}$

Velocity in $x_{i}$-direction, $\mathrm{m} / \mathrm{s}$

Overall velocity vector, $\mathrm{m} / \mathrm{s}$

Velocity of air, $\mathrm{m} / \mathrm{s}$

Channel aspect ratio

Width of passage, $\mathrm{m}$

Width of a single V-perforated baffle, $m$

Relative baffles width

Axial coordinate, $\mathrm{m}$

Dimensionless distance from walls

Pressure drop crossways test section, $\mathrm{Pa}$

Pressure drop crossways orifice plate, $\mathrm{Pa}$ 


\section{Greek Symbols}

$\begin{array}{ll}\alpha & \text { Flow attack angle, degree } \\ \beta & \text { Open area ratio, \% } \\ \mu & \text { Dynamic viscosity, } N \mathrm{~s} / \mathrm{m}^{2} \\ \mu_{\mathrm{t}} & \text { Turbulent viscosity, } \mathrm{Ns} / \mathrm{m}^{2} \\ \rho & \text { Density, } \mathrm{kg} / \mathrm{m}^{3} \\ \varphi & \text { Half angle of baffle tip, degree } \\ \eta & \text { Thermo-hydraulic performance parameter } \\ \varepsilon & \text { Turbulent kinetic energy dissipation rate, } \mathrm{m}^{2} / \mathrm{s}^{3} \\ C_{\mu}, C_{\varepsilon 1}, C_{\varepsilon 2} & \text { RNG } k-\varepsilon \text { model constant }\end{array}$

\section{Subscript}

CFD

SAH

Computational fluid dynamics

Solar air heater

\section{References}

1. Kumar, A.; Kim, M.-H. Numerical optimization of solar air heaters having different types of roughness shapes on the heated plate-Technical note. Energy 2014, 72, 731-738. [CrossRef]

2. Djamel, S.; Houari, A.; Redouane, B.; Youcef, K. Enhancement of heat transfer in a rectangular channel with perforated baffles. Appl. Therm. Eng. 2016, 101, 156-164.

3. Kumar, R.; Chauhan, C.; Muneesh, S.; Ashutosh, S.; Kumar, A. Experimental investigation of effect of flow attack angle on thermohydraulic performance of air flow in a rectangular channel with discrete V-pattern baffle on the heated plate. Adv. Mech. Eng. 2016, 8, 1-12. [CrossRef]

4. Kumar, A.; Kim, M.-H. Convective heat transfer enhancement in solar air channels. Appl. Therm. Eng. 2015, 89, 239-261. [CrossRef]

5. Kumar, A.; Saini, R.P.; Saini, J.S. An experimental investigation of enhanced heat transfer due to a gap in a continuous multiple V-rib arrangement in a solar air channel. J. Enhanc. Heat Trans. 2014, 21, 21-49. [CrossRef]

6. Won, S.Y.; Burgess, N.K.; Peddicord, S.; Ligrani, P.M. Spatially resolved surface heat transfer for parallel rib turbulators with $45 \mathrm{deg}$ orientations including test surface conduction analysis. J. Heat Transf. 2004, 126, 193-201. [CrossRef]

7. Khanoknaiyakarn, C.; Kwankaomeng, S.; Promvonge, P. Thermal performance enhancement in solar air heater channel with periodically V-shaped baffles. In Proceedings of the International Conference on Utility Exhibition on Power and Energy Systems: Issues and Prospectus for Asia (ICUE), Pattaya City, Thailand, 28-30 September 2011; pp. 1-6.

8. Sriromreun, P.; Thianpong, C.; Promvonge, P. Experimental and numerical study on heat transfer enhancement in a channel with Z-shaped baffles. Int. Commun. Heat Mass Transf. 2012, 39, 945-952. [CrossRef]

9. Bopche, S.B.; Tandale, M.S. Experimental investigation on heat transfer and frictional characteristics of a turbulator roughened solar air heater channel. Int. J Heat Mass Transf. 2009, 52, 2834-2848. [CrossRef]

10. Skullong, S.; Kwankasmeng, S.; Thianpong, C.; Promvonge, P. Thermal performance of turbulent flow in a solar air heater channel with rib-groove turbulators. Int. Comm. Heat Mass Transf. 2014, 50, 34-43. [CrossRef]

11. Karwa, R.; Maheshwari, B.K. Heat transfer and friction in an asymmetrically heated rectangular channel with half and fully perforated baffles at different pitches. Int. Commun. Heat Mass Transf. 2009, 36, 264-268. [CrossRef]

12. Shin, S.; Kwak, J.S. Effect of hole shape on the heat transfer in a rectangular channel with perforated blockage walls. J. Mech. Sci. Tech. 2008, 22, 1945-1951. [CrossRef]

13. Zhou, G.; Ye, Q. Experimental investigations of thermal and flow characteristics of curved trapezoidal winglet type vortex generators. Appl. Therm. Eng. 2012, 37, 241-248. [CrossRef]

14. Bekele, A.; Mishra, M.; Dutta, S. Effects of delta-shaped obstacles on the thermal performance of solar air heater. Adv. Mech. Eng. 2011, 3. [CrossRef] 
15. Chompookham, T.; Thianpong, C.; Kwankaomeng, S.; Promvonge, P. Heat transfer augmentation in a wedge ribbed channel using winglet vortex generators. Int. Commun. Heat Mass Transf. 2010, 37, 163-169. [CrossRef]

16. Abene, A.; Dubois, V.; Ray, M.L.; Ouagued, A. Study of a solar air flat plate collector: Use of obstacles and application for the drying of grape. J. Food Eng. 2004, 65, 15-22. [CrossRef]

17. Ozgen, F.; Esen, M.; Esen, H. Experimental investigation of thermal performance of a double-flow solar air heater having aluminum cans. Renew. Energy 2009, 34, 2391-2398. [CrossRef]

18. Thianpong, C.; Yongsiri, K.; Nanan, K.; Eiamsa-ard, S. Thermal performance evaluation of heat exchangers fitted with twisted ring turbulators. Int. Commun. Heat Mass Transf. 2012, 39, 861-868. [CrossRef]

19. Eiamsa-ard, S.; Wongcharee, K.; Eiamsa-ard, P.; Thianpong, C. Heat transfer enhancement in a tube using delta-winglet twisted tape insets. Appl. Therm. Eng. 2010, 30, 310-318. [CrossRef]

20. Chamoli, S.; Thakur, N.S. Correlations for solar air heater channel with V-shaped perforated baffles as roughness elements on absorber plate. Int. J. Sustain. Energy 2013, 35, 1-20. [CrossRef]

21. Alam, T.; Saini, R.P.; Saini, J.S. Experimental investigation of thermohydraulic performance of a rectangular solar air heater duct equipped with V-shaped perforated blocks. Adv. Mech. Eng. 2014, 6. [CrossRef]

22. Tamna, S.; Skullong, S.; Thianpong, C.; Promvonge, P. Heat transfer behaviors in a solar air heater channel with multiple V-baffle vortex generators. Sol. Energy 2014, 110, 720-735. [CrossRef]

23. Gawande, V.B.; Dhoble, A.S.; Zodpe, D.B. CFD analysis to study effect of circular vortex generator placed in inlet section to investigate heat transfer aspects of solar air heater. Sci. World J. 2014, 2014. [CrossRef] [PubMed]

24. Promvonge, P.; Jedsadaratanachai, W.; Kwankaomeng, S. Numerical study of laminar flow and heat transfer in square channel with $30^{\circ}$ inline angled baffle turbulators. Appl. Therm. Eng. 2010, 30, 1292-1303. [CrossRef]

25. Garg, A.; Dhingra, S.; Singh, G. CFD analysis of laminar heat transfer in a channel provided with baffles: Diamond shaped baffles of different angle and rectangle. Int. J. Enhanc. Res. Sci. Tech. Eng. 2014, 7, 267-276.

26. Jedsadaratanachai, W.; Boonloi, A. Effect of blockage ratio and pitch ratio on thermal performance in a square channel with $30^{\circ}$ double V-baffles. Case Stud. Therm. Eng. 2014, 4, 118-128. [CrossRef]

27. Yadav, A.; Samant, T.; Varshney, L. A CFD based analysis of solar air heater having V-shaped perforated blocks on absorber plate. Int. Res. J. Eng. Tech. 2015, 2, 822-829.

28. Yadav, S.; Bhagoria, J.L. A numerical investigation of square sectioned transverse rib roughened solar air heater. Int. J. Therm. Sci. 2014, 79, 111-131. [CrossRef]

29. Karmare, S.V.; Tikekar, A.N. Analysis of fluid flow and heat transfer in a grit roughened surface solar air heater using CFD. Sol. Energy 2010, 84, 409-417. [CrossRef]

30. Kumar, S.; Saini, R.P. CFD based performance analysis of a solar air heater duct provided with artificial roughness. Renew. Energy 2009, 34, 1285-1291. [CrossRef]

31. Soi, A.; Singh, R.; Bhushan, B. Effect of roughness element pitch on heat transfer and friction characteristics of artificially roughened solar air heater duct. Int. J. Adv. Eng. Tech. 2010, 3, 339-346.

32. Yadav, S.; Bhagoria, J.L. A CFD based thermo-hydraulic performance analysis of an artificially roughened solar air heater having equilateral triangular sectioned rib roughness on the absorber plate. Int. J. Heat Mass Transf. 2014, 70, 1016-1039. [CrossRef]

33. Singh, S.; Singh, B.; Hans, V.S.; Gill, R.S. CFD (computational fluid dynamics) investigation on Nusselt number and friction factor of solar air heater duct roughened with non-uniform cross-section transverse rib. Energy 2015, 84, 509-517. [CrossRef]

34. Kumar, A.; Kim, M.-H. Effect of roughness width ratios in discrete multi V-rib with staggered rib roughness on overall thermal performance of solar air channel. Sol. Energy 2015, 119, 399-414. [CrossRef]

35. Fluent 6.3 User's Guide; Fluent Inc.: Lebanon, NH, USA, 2006.

36. Kumar, A.; Kim, M.-H. Heat transfer and fluid flow characteristics in air duct with various V-pattern rib roughness on the heated plate: A comparative study. Energy 2016, 103, 75-85. [CrossRef]

37. Webb, R.L.; Eckert, E.R.G. Application of rough surface to heat exchanger design. Int. J. Heat Mass Transf. 1972, 15, 1647-1658. [CrossRef]

38. Klein, S.J.; McClintock, A. Describing uncertainties in single-sample experiments. Mech. Eng. 1953, 75, 3-8.

(C) 2016 by the authors; licensee MDPI, Basel, Switzerland. This article is an open access article distributed under the terms and conditions of the Creative Commons Attribution (CC-BY) license (http://creativecommons.org/licenses/by/4.0/). 